\title{
Investigating Knowledge Management Status among Faculty Members of Kerman University of Medical Sciences based on the Nonaka Model in 2015
}

\author{
Leila Vali ${ }^{1}$, Azar Izadi ${ }^{2}$, Yunes Jahani ${ }^{3,4}$, Maryam Okhovati ${ }^{5}$
}

${ }^{1}$ Assistant Professor, Environmental Health Engineering Research Center, Kerman University of Medical Science, Kerman, Iran

${ }^{2}$ M.Sc. in Health Care Management, School of Management and Medical Information, Kerman University of Medical sciences, Kerman, Iran

${ }^{3}$ Assistant Professor, Research Center for Modeling in Health, Institute for Futures Studies in Health, Kerman University of Medical Sciences, Kerman, Kerman, Iran

${ }^{4}$ Assistant Professor, Department of Biostatistics and Epidemiology, School of Public Health, Kerman University of Medical Sciences, Kerman, Iran

${ }^{5}$ Associate Professor, Neuroscience Research Center, Institute of Neuropharmacology, Kerman University of Medical Sciences, Kerman, Iran

Type of article: Original

\begin{abstract}
Introduction: Education and research are two major functions of universities, which require proper and systematic exploitation of available knowledge and information. Therefore, it is necessary to investigate the knowledge management status in an education system by considering the function of faculty members in creation and dissemination of knowledge. This study was conducted to investigate the knowledge management status among faculty members of the Kerman University of Medical Sciences based on the Nonaka and Takeuchi models in 2015.

Methods: This was a descriptive-analytical and cross-sectional study. It was conducted on 165 faculty members at the Kerman University of Medical Sciences, who were selected from seven faculties as weighted using a random stratified sampling method. The Nonaka and Takeuchi knowledge management questionnaire consists of 26 questions in four dimensions of socialization, externalization, internalization, and combination. Scoring of questions was conducted using the five-point Likert scale. To analyze data, independent t-test, one-way ANOVA, Pearson correlation coefficients, and the Kruskal-Wallis test were employed.

Results: The four dimensions in the Nonaka and Takeuchi model are based on optimal indicators (3.5), dimensions of combination, and externalization with an average of 3.3 were found in higher ranks and internalization and socialization had averages of 3.1 and 3. According to the findings of this study, the average knowledge management among faculty members of the Kerman University of Medical Sciences was estimated to be 3.1, with a bit difference compared to the average. According to the results of $\mathrm{t}$-tests, there was no significant relationship between gender and various dimensions of knowledge management $(p>0.05)$. The findings of Kruskal-Wallis showed that there is no significant relationship between variables of age, academic rank, and type of faculty with regard to dimensions of knowledge management ( $p>0.05$ ). In addition, according to the results of Pearson tests, there is no significant relation between employment history and dimensions of knowledge management $(\mathrm{p}>0.05)$.

Conclusion: Considering the function and importance of knowledge management in education and research organizations including universities, it is recommended to pay comprehensive attention to establishment of knowledge management and knowledge sharing in universities and provide the required background to from research teams and communication networks inside and outside universities.
\end{abstract}

Keywords: Knowledge Management; Nonaka and Takeuchi Model; Faculty Members

\section{Corresponding author:}

Azar Izadi, School of Management and Medical Information, Kerman University of Medical sciences, Kerman, Iran. Tel: +98.3431325145, Fax: +98.3431325221, Email: azar.izadi@gmail.com

Received: October 04, 2015, Accepted: March 12, 2016, Published: August 2016

iThenticate screening: March 12, 2016, English editing: July 02, 2016, Quality control: August 01, 2016

(C) 2016 The Authors. This is an open access article under the terms of the Creative Commons Attribution-NonCommercialNoDerivs License, which permits use and distribution in any medium, provided the original work is properly cited, the use is non-commercial and no modifications or adaptations are made. 


\section{Introduction}

Today, organizations are moving from a world dependent upon physical and material resources to a world that depends on information and knowledge (1). In this period, one of the most important and valuable capital of each organization is knowledge, which is regarded as intellectual capital of organization (2). Therefore, this period is referred to as a knowledge-oriented period (3). Knowledge is a perception obtained from experience, reasoning, direct perception, and learning (4). Rapid changes and increasing development of knowledge and information makes each organization do its best to properly utilize it (5). Since correct knowledge management will result in obtaining a competitive advantage in a dynamic and variable environment (2), the ability of organizations to attract and utilize intra-and inter-organizational knowledge is an applicable solution to create a competitive advantage (6). Knowledge management $(\mathrm{KM})$ is considered to be an organized process to identify, collect, organize, and process data to create knowledge (7). This is an approach that enforces organizational knowledge and skill in order to create value and promote organizational efficiency (8) and assist problem-solving activities, dynamic learning, strategic planning, and decision-making (9) and is utilized as one of the main and major components for organizations to survive and maintain competitive ability with the aim of encouraging innovation (10). By attracting new knowledge to the system, combined with effective management of that knowledge, this process can be the most important factor for change in an organization (11). In other words, performance of knowledge management oversees a series of systematic actions that provide access to maximum stability and effective efficiency of knowledge (12). The authors believe that the 1980s was the decade of quality movement and 1990s was a reengineering decade, while this decade is the decade of knowledge management (3). In Iran, knowledge management has been specifically considered since the late 1990s (13). In recent decades, KM has been praised as one of the major changes in knowledge and information studies, as well as the science of management (14). The main role of KM in organizations is to create a learning environment in such a way that enables employees to experience various types of learning and share their knowledge and wisdom with other employees, customers, and even competitors (15). In most KM models, a 4-stage process is introduced that consists of knowledge creating, knowledge saving, knowledge application, and the knowledge sharing process (16), where knowledge creating and sharing are regarded as the two main and key activities of KM (17). One of the ways of measuring KM is the amount of implicit and explicit knowledge sharing in an organization (18). Since the competitive dimension of each organization is an effective creation and transfer of knowledge to the organization, identifying effective knowledge sharing and transfer inside the organization and the organization's KM is required (19). On the one hand, human resources, technologies, the ability to apply knowledge, organizational structure and culture are factors that affect the success and development of a KM program (20). On the other hand, there are major obstacles on the way of KM that can be classified into 5 main classes including organizational, cultural, political, technical and technologic factors (11).

Until now, 26 models have been presented for KM, most of which are relatively similar in terms of content, but with words and phrases in a different order. Of these models, Nonaka and Takeuchi is one of the best models in terms of explaining the way to produce knowledge (12). This model concentrates on two types of implicit and explicit knowledge to plan organizational learning theory and pays attention to the method of converting these knowledge types into each other, as well as a way of creating it in all organizational (personal, group, and organizational) levels (21). Relying on the main hypothesis that an individual's knowledge is a major capital of the organization requires coordination and integration and believing that this major feature, knowledge, consists of a hidden dimension. By creating a dynamic and irrefrangible interaction between implicit and explicit knowledge, it presents four major strategies in KM, including socialization, externalization, combination, and internalization, that are effective not only in KM processes, but also in creating new knowledge (22). Health care organizations are complex organizations with unique features that differentiate them from other organizations. Identification and a deep understanding of KM within an organization assists productivity and optimized use of resources. KM in health system can be useful for patients and clients, as well as employees and different sections of a system and for the whole public health (23). In organizations, including health system and hospitals, there is knowledge specific to the field. According to the report by Cranfield University in 1998, approximately $61 \%$ of organizations believe that their required knowledge is available in the organization (24). However, the problem is identifying and finding it. In addition, better decision-making (86\%), quick response to key matters $(67 \%)$, productivity improvements $(67 \%)$, cost reduction $(70 \%)$, sharing best practices and actions $(60 \%)$, an increase in profits $(53 \%)$, providing new job opportunities $(58 \%)$, increasing market share $(42 \%)$, as well as attracting and retaining better and more efficient staff $(42 \%)$ are among the primary objectives of $\mathrm{KM}$ in an organization (24). Universities and higher education institutes in every nation are regarded as the main hub of knowledge creation and training graduates plays an important role in increasing development of countries, in line with assisting realization of Iran's vision objectives in 2025 (25). In addition, special attention is paid to the fact that Universities of medical sciences have many 
responsibilities and are connected to various spectrums of addresses, including students, employees, professors, staffs and the people that are regarded as main centers of knowledge production and dissemination that play a vital role in advancing the scientific knowledge of the society (26). Several studies have investigated KM status among faculty members. For instance, the study of KM status in Shahid Chamran University of Ahvaz showed that KM utility among faculty members of this University is lower than average and the difference between the average scores of KM for faculty members was significant with an optimal indicator of 3.5. Furthermore, externalization in KM in Shahid Chamran University of Ahvaz occurs at a high level and socialization and internalization are lower. These results show the tendency of faculty members to share knowledge with others (5). In addition, in a similar study conducted in Ferdowsi University of Mashhad, this result was obtained that internalization of KM in Ferdowsi University of Mashhad occurs at a high level and socialization, externalization, and combination are lower. Within this ranking of KM dimensions states, managers are more willing to internalize knowledge and compete with others, rather than sharing and exchanging their knowledge and experience with others (27). A study conducted at the Isfahan University of Medical Sciences showed that all 6 process of KM, including knowledge identification, knowledge acquisition and collection, knowledge development, knowledge sharing and dissipation, knowledge, using knowledge, knowledge sharing and maintenance, in all areas for the establishments were lower than average (28). Results of the study conducted in the Kerman University of Medical Sciences showed that KM and its components among employees of staff units in various departments (educational deputy, deputy of research and technology, deputy of development and resource management, food and drug department, deputy of health, cultural and student affairs, and deputy of treatment) are at a relatively suitable status. In this study, the average score of components, including knowledge acquisition, knowledge use, knowledge and evaluation, are estimated to be lower than average and other components, including knowledge identification, knowledge maintenance, knowledge sharing and development, had an average score at a relatively optimal level and generally the total score of KM was optimal (26).

The latest educational ranking of Iran Universities of medical sciences in 2015 showed that Shahid Beheshti (100 score), Tehran (92.97), Shiraz (92.35), Tabriz (75.87), and Kerman (75.28) University of Medical Sciences are the top Universities of medical sciences in Iran. In this ranking, the status of Universities and Universities of medical sciences has been evaluated in terms of 5 fields, including education development, governance, KM, quality development of education, and movement in line with the macro scientific plans of the country (29). Due to the relatively high score of the Kerman University of Medical Sciences in this ranking, the research team decided to investigate knowledge management status among faculty members of the Kerman University of Medical Sciences, considering the proper scientific status of this university and in accordance with completing results of conducted study on staff areas of this University, as well as the importance of KM in Universities as centers of knowledge dissipation.

\section{Material and Methods}

This was a descriptive-analytic cross-sectional study conducted in 2015. The study population was 410 faculty members of the Kerman University of Medical Sciences who were working in seven schools of medicine, dentistry, pharmacy, Paramedicine, nursing and midwifery, and the school of management and medical information. Using stratified random sampling, 165 members were selected as a sample. Due to unknown variance in statistical society, this sample was selected to determine sample variance by conducting a pilot study on 30 participants. After entering data in SPSS and a pre-estimation of variance, sample size was determined. Then, considering the number of faculty members of each school, the number of selected members from each school and each department was determined. Considering the number of faculty members of each school and total sample size of the study, 92, 26, 12, 11, 5, 10, and 9 members were selected from schools of medicine, dentistry, pharmacy, nursing and midwifery, Paramedicine, management, and medical information schools, respectively. To collect data, the Nonaka and Takeuchi management questionnaire was used; the validity and reliability of which had been verified in the Masters' thesis of Shabani Varaki (2004). This questionnaire consists of 26 questions that investigate four components of KM, including socialization, externalization, internalization, and combination. Here, for estimating externalization, combination, internalization and socialization, 5 (1-5), 11 (6-16), 4 (17-20) and 6 (21-26) questions were attributed, respectively. Scoring of questions was conducted using a 5-point Likert scale (strongly agree, agree, neither agree or disagree, disagree, and strongly disagree). The highest and lowest scores (5 and 1, respectively) belong to the strongly agree and strongly disagree items. Considering a 5-scale scoring system of Likert (the highest and lowest score for each question to be 5 and 1, respectively), as well as the total number of questions in questionnaire (26), scores of 1-26 show very weak KM status, 27-52 show weak KM status, 53-78 show medium KM status, 79-104 show strong KM status, and 105-130 show very strong KM status. To estimate the highest score for each school, the number of 
faculty members participating in the study was multiplied by the 26 questions of the questionnaire and then the highest score (5) to determine the KM score for each school. In this study, KM was investigated as a dependent variable and demographic details of participants, including age, gender, academic rank, employment history, and intended school, were studied as independent variables. Data obtained from questionnaires were analyzed using SPSS statistical software. To determine the status of KM dimensions among faculty members of various schools, descriptive statistics were employed. To determine the relationship between demographic variables and KM dimensions, independent t-test one-way ANOVA, Pearson correlation coefficient and non-parametric KruskalWallis tests were used. To make the comparison of results of this study with similar studies, we referred to documents from the study conducted by Parsa et al. (5), and obtained averages for KM management were compared with hypothetical average of 3.5 (as the median). In addition, to examine research hypothesis to see whether there is a significant difference between KM status in the Kerman University of Medical Sciences with an optimal indicator, one-sample t-test was used with a hypothetical optimal indicator of 3.5 (t-value) (5).

\section{Results}

Based on the findings of this study, $56.4 \%$ of participants were males. With regard to scientific rank, $71.5 \%$ were assistant professors and $44.8 \%$ of them were between 40 and 49 years of age. Faculty members of the School of Medicine accounted for $55.8 \%$ of the studied samples. Average employment history of faculty members in the studied Universities was $164 \pm 8.07$ years. Frequency distribution of variables is shown in detail in Table 1 based on each school. Results of one-sample t-test conducted to investigate the optimality of the KM components in the Kerman University of Medical Sciences are shown in Table 2. According to the findings of this test, the average scores of faculty members in all KM components were lower than the optimal indicator and this difference was significant for all four components $(\mathrm{p}<0.05)$. However, score differences regarding externalization and combination with an optimal indicator were lower than other variables. The mean of scores obtained in various schools is shown in Table 3. As can be seen in this table, the obtained scores in the schools of Medicine, Dentistry, Management, and Medical Information were higher than the expected value that demonstrates optimal status of KM in these schools. The lowest score belongs to Paramedicine School. Results from investigating the relation between demographic variables and $\mathrm{KM}$ components are shown in Table 4. According to t-test results, no significant relationship was observed between gender and other dimensions of $\mathrm{KM}(\mathrm{p}>0.05)$.

Table 1. Frequency distribution of demographic features of studied faculty members in the schools of the Kerman University of Medical Sciences

\begin{tabular}{|c|c|c|c|c|c|c|c|c|c|c|c|c|c|c|c|}
\hline \multirow{3}{*}{\multicolumn{2}{|c|}{ Demographic variables }} & \multicolumn{14}{|c|}{ College } \\
\hline & & \multicolumn{2}{|c|}{ Medicine } & \multicolumn{2}{|c|}{ Dentistry } & \multicolumn{2}{|c|}{ Pharmacy } & \multicolumn{2}{|c|}{$\begin{array}{l}\text { Nursing \& } \\
\text { Midwifery }\end{array}$} & \multicolumn{2}{|c|}{ Paramedicine } & \multicolumn{2}{|c|}{ Health } & \multicolumn{2}{|c|}{$\begin{array}{l}\text { Management and } \\
\text { Medical Information }\end{array}$} \\
\hline & & $\mathrm{n}$ & $\%$ & $\mathrm{n}$ & $\%$ & $\mathrm{n}$ & $\%$ & $\mathrm{n}$ & $\%$ & $\mathrm{n}$ & $\%$ & $\mathrm{n}$ & $\%$ & $\mathrm{n}$ & $\%$ \\
\hline \multirow[t]{2}{*}{ Gender } & Female & 35 & 38 & 14 & 54 & 7 & 58 & 9 & 81.8 & 2 & 40 & 3 & 30 & 5 & 56 \\
\hline & Male & 57 & 62 & 12 & 46 & 5 & 42 & 2 & 18.1 & 3 & 60 & 7 & 70 & 4 & 44 \\
\hline \multirow[t]{4}{*}{ Age (year) } & $<40$ & 16 & 17 & 12 & 46 & 5 & 42 & 3 & 27.2 & 0 & 0 & 3 & 30 & 3 & 33 \\
\hline & $40-49$ & 45 & 49 & 7 & 27 & 7 & 58 & 5 & 45.4 & 5 & 100 & 2 & 20 & 4 & 45 \\
\hline & $50-59$ & 27 & 29 & 7 & 27 & 0 & 0 & 3 & 27.2 & 0 & 0 & 4 & 40 & 2 & 22 \\
\hline & $\geq 60$ & 4 & 5 & 0 & 0 & 0 & 0 & 0 & 0 & 0 & 0 & 1 & 10 & 0 & 0 \\
\hline \multirow{4}{*}{$\begin{array}{l}\text { Academic } \\
\text { rank }\end{array}$} & Instructor & 1 & 1 & 1 & 4 & 1 & 8 & 6 & 54.5 & 4 & 80 & 1 & 10 & 2 & 22 \\
\hline & $\begin{array}{l}\text { Assistant } \\
\text { Professor }\end{array}$ & 70 & 76 & 18 & 69 & 11 & 92 & 5 & 45.4 & 1 & 20 & 7 & 70 & 6 & 67 \\
\hline & $\begin{array}{l}\text { Associate } \\
\text { Professor }\end{array}$ & 19 & 21 & 7 & 27 & 0 & 0 & 0 & 0 & 0 & 0 & 0 & 0 & 1 & 11 \\
\hline & Professor & 2 & 2 & 0 & 0 & 0 & 0 & 0 & 0 & 0 & 0 & 2 & 20 & 0 & 0 \\
\hline \multirow{3}{*}{$\begin{array}{l}\text { Service } \\
\text { record } \\
\text { (year) }\end{array}$} & $<10$ & 20 & 22 & 10 & 38 & 5 & 42 & 2 & 18.1 & 0 & 0 & 3 & 30 & 3 & 33 \\
\hline & $10-20$ & 42 & 46 & 9 & 35 & 4 & 33 & 3 & 27.2 & 2 & 40 & 3 & 30 & 2 & 22 \\
\hline & $\geq 20$ & 29 & 32 & 7 & 27 & 3 & 25 & 6 & 54.5 & 3 & 60 & 4 & 40 & 4 & 45 \\
\hline \multirow{3}{*}{$\begin{array}{l}\text { Experience } \\
\text { of } \\
\text { academic } \\
\text { staff }\end{array}$} & $<10$ & 22 & 24 & 11 & 42 & 7 & 58 & 4 & 36.3 & 0 & 0 & 4 & 40 & 4 & 45 \\
\hline & $10-20$ & 41 & 44 & 11 & 42 & 5 & 42 & 3 & 27.2 & 5 & 100 & 2 & 20 & 4 & 45 \\
\hline & $\geq 20$ & 29 & 32 & 4 & 16 & 0 & 0 & 4 & 36.3 & 0 & 0 & 4 & 40 & 1 & 10 \\
\hline
\end{tabular}


http://www.ephysician.ir

Table 2. One-sample t-test to investigate the optimality of KM components in the Kerman University of Medical Sciences

\begin{tabular}{|l|l|l|l|l|l|}
\hline Elements of knowledge management & Average & Optimal indicators & $\mathrm{t}$ & $\mathrm{df}$ & $\mathrm{p}$-value \\
\hline Externalization & 3.3 & 3.5 & 53.1 & 164 & 0.05 \\
\hline Combination & 3.3 & 3.5 & 60.7 & 164 & 0.05 \\
\hline Internalization & 3.1 & 3.5 & 40.1 & 164 & 0.05 \\
\hline Socialization & 3 & 3.5 & 53 & 164 & 0.05 \\
\hline total & 3.1 & 3.5 & 73 & 164 & 0.05 \\
\hline
\end{tabular}

Table 3. Average expected and obtained score in various schools of Kerman University of Medical Sciences

\begin{tabular}{|l|l|l|l|}
\hline College & Number of staff & Average scores expected & Average scores \\
\hline Medicine & 92 & 11960 & 7150 \\
\hline Dentistry & 26 & 3380 & 4290 \\
\hline Pharmacy & 12 & 1560 & 1560 \\
\hline Nursing and Midwifery & 11 & 1430 & 780 \\
\hline Paramedicine & 5 & 650 & 0 \\
\hline Health & 10 & 1300 & 2990 \\
\hline Management and Medical Information & 9 & 1170 & 1690 \\
\hline
\end{tabular}

Table 4. Investigation of the relationship between demographic variables among studied faculty members with KM components based on the Nonaka and Takeuchi model

\begin{tabular}{|l|l|l|l|l|}
\hline \multirow{2}{*}{ Variable } & \multicolumn{4}{l|}{ Elements of knowledge management (p-value) } \\
\cline { 2 - 5 } & Socialization & Externalization & Combination & Internalization \\
\hline Age & 0.30 & 0.49 & 0.31 & 0.64 \\
\hline Sex & 0.28 & 0.44 & 0.86 & 0.39 \\
\hline Scientific level & 0.68 & 0.77 & 0.97 & 0.44 \\
\hline Service record & 0.52 & 0.84 & 0.24 & 0.48 \\
\hline Experience of academic staff & 0.16 & 0.54 & 0.60 & 0.37 \\
\hline College & 0.12 & 0.65 & 0.29 & 0.21 \\
\hline
\end{tabular}

Results from Kruskal-Wallis tests showed that there is no significant relation between variables of gender, academic rank, and type of school with KM dimensions ( $p>0.05$ ). In addition, according to results from the Pearson test, no significant relationship was observed between employment history and KM dimensions ( $>0.05)$. Frequency distribution of each KM dimension in various schools is shown in Table 5. As can be seen from this table, the schools of management and medical information have been more successful in terms of combination and socialization; the schools of health and pharmacy have been more successful in terms of externalization; and the schools of health and medicine have been more successful in terms of internalization. The schools of medicine and nursing excelled in terms of combination, the nursing and paramedical schools in terms of socialization, the schools of management and medical information in terms of externalization, and the pharmacy and paramedical schools were of lowest ranked in terms of internalization.

\section{Discussion}

Investigating KM status among faculty members of the Kerman University of Medical Sciences demonstrates that, in this University, $\mathrm{KM}$ is lower than average. In addition, dimensions of externalization and combination, having similar scores, are at the highest levels, and internalization and socialization components are the lowest. Higher scores in combination and externalization show that development, entrepreneurship, cooperation, and participation in knowledge sharing is valuable in this university. While regarding exchange of knowledge as important, participants have sufficient motivation to convey their implicit and personal knowledge to others and relate their personal experiences to less-experienced people. In addition, participants are willing to use objective samples, examples, and simulations to clarify their intention and they have the ability to create motivation in others through the exchange professional thoughts and beliefs and use the community network to identify their tasks. Externalization rankings show a relative weakness of the university in organizing and recording available documents. In addition, socialization is ranked last, showing weak performance for inter-organization networks in exchanging knowledge and summaries of experiences and learning not being written or coherent, as well as the team not cooperating with independent research teams. Weaknesses in inter-organization networks and improper communications are among those cases that can be mentioned as problems regarding KM identified in this study due 
to achieving a low score in socialization. Furthermore, of the seven schools under study, the school of health and Paramedicine School received the highest and lowest scores in all KM dimensions, respectively.

Table 5. Frequency distribution of KM dimensions status based on the Nonaka and Takeuchi model among studied faculty members at the Kerman University of Medical Sciences

\begin{tabular}{|c|c|c|c|c|c|c|}
\hline \multirow{2}{*}{$\begin{array}{l}\text { Elements of knowledge } \\
\text { management }\end{array}$} & \multirow[t]{2}{*}{ College } & \multicolumn{5}{|c|}{ The status of knowledge management (\%) } \\
\hline & & $\begin{array}{l}\text { Completely } \\
\text { agree }\end{array}$ & agree & $\begin{array}{l}\text { No } \\
\text { idea }\end{array}$ & disagree & $\begin{array}{l}\text { Completely } \\
\text { disagree }\end{array}$ \\
\hline \multirow{7}{*}{ Externalization } & Medicine & 3.4 & 23.6 & 11 & 56.9 & 4.7 \\
\hline & Dentistry & 8.4 & 36.1 & 10.7 & 42.3 & 2.3 \\
\hline & Pharmacy & 6.6 & 26.6 & 18.3 & 48.3 & 0 \\
\hline & Nursing and Midwifery & 3.6 & 49 & 9 & 34.5 & 3.6 \\
\hline & Paramedicine & 0 & 20 & 24 & 52 & 4 \\
\hline & Health & 8 & 28 & 12 & 44 & 8 \\
\hline & $\begin{array}{l}\text { Management and } \\
\text { Medical Information }\end{array}$ & 2.2 & 20 & 20 & 53.3 & 4.4 \\
\hline \multirow[t]{7}{*}{ Combination } & Medicine & 1.3 & 23 & 14.4 & 51.9 & 9.1 \\
\hline & Dentistry & 4.5 & 19.9 & 13.9 & 50.6 & 10.8 \\
\hline & Pharmacy & 3.7 & 25 & 33.3 & 32.5 & 5.3 \\
\hline & Nursing and Midwifery & 0.8 & 34.7 & 19 & 38.8 & 6.6 \\
\hline & Paramedicine & 1.8 & 23.6 & 20 & 45.4 & 9 \\
\hline & Health & 8.1 & 12.7 & 20.9 & 45.5 & 8.1 \\
\hline & $\begin{array}{l}\text { Management and } \\
\text { Medical Information }\end{array}$ & 6 & 18.1 & 28.2 & 44.4 & 3 \\
\hline \multirow[t]{7}{*}{ Internalization } & Medicine & 35.3 & 26.9 & 19.5 & 48 & 1.9 \\
\hline & Dentistry & 1.9 & 31.7 & 21.1 & 37.5 & 7.6 \\
\hline & Pharmacy & 2 & 25 & 41.6 & 29.1 & 2 \\
\hline & Nursing and Midwifery & 4.5 & 43.1 & 18.1 & 31.8 & 2.2 \\
\hline & Paramedicine & 0 & 5 & 15 & 70 & 10 \\
\hline & Health & 12.5 & 22.5 & 27.5 & 37.5 & 0 \\
\hline & $\begin{array}{l}\text { Management and } \\
\text { Medical Information }\end{array}$ & 8.3 & 16.6 & 30.5 & 44.4 & 0 \\
\hline \multirow[t]{7}{*}{ Socialization } & Medicine & 2.1 & 35 & 16.1 & 44.3 & 2.3 \\
\hline & Dentistry & 5.1 & 33.3 & 16 & 38.4 & 7.6 \\
\hline & Pharmacy & 2 & 19.4 & 14.5 & 13.1 & 0.6 \\
\hline & Nursing and Midwifery & 0 & 46.9 & 21.2 & 3.3 & 1.5 \\
\hline & Paramedicine & 0 & 10 & 16.6 & 60 & 10 \\
\hline & Health & 8.3 & 25 & 31.6 & 33.3 & 1.6 \\
\hline & $\begin{array}{l}\text { Management and } \\
\text { Medical Information }\end{array}$ & 5.5 & 33.3 & 22.2 & 35.1 & 3.7 \\
\hline
\end{tabular}

Results of a similar study in Shahid Chamran University of Ahvaz, showed that KM status in this University was lower than average. Externalization in KM was ranked highest and combination, socialization, and internalization were ranked lower. Similar to the present study, the tendency of faculty members, in terms of knowledge sharing and participation in research teams, was estimated to be favorable and weakness of the organizational networks is the main reason of the relatively low KM status for this University (5). KM status in the Ahvaz University of Medical Sciences, similar to the Kerman University of Medical Sciences, was lower than average and externalization and combination are ranked lowest, which correlates closely with the results of this study. Similar organizational environments and cultures are a reason for the similar results of this study with the published study. Socialization is of higher rank relative to internalization at the Ahvaz University of Medical Sciences, while in the Kerman University of Medical Sciences, socialization is ranked lower than internalization. The reason for this difference is the better performance of the faculty members of the Ahvaz University of Medical Sciences in terms of forming independent research teams and using inter-organizational networks. In another study conducted at a military research center in Tehran, the status of this research center was estimated to be lower than average in terms 
of being knowledge-oriented and utilizing knowledge capitals. The KM components ranked socialization, externalization, combination and internalization from high to low in terms of obtained scores. At this research center, the use of research teams and organizational networks has resulted in superiority with regard to KM socialization, while inter-organizational establishment is still weak (30). The KM status in this military research center is similar to the KM status in the present study, but ranking of the KM dimensions for this research center is completely different from the Kerman University of Medical Sciences and the main reason for this difference is a different organizational structure for Kerman University of Medical Sciences compared to the organizational structure of the military research center. Knowledge sharing is regarded as important, while exchange of knowledge by forming independent research teams and inter-organizational networks, using web services, and high motivation of staff relative to knowledge sharing are among the differences between the military research center and the Kerman University of Medical Sciences. Another study conducted at Isfahan University showed that knowledge combination scored highest. Externalization, internalization and socialization lie in the later ranks (31). Results of this study were similar to our study in terms of the KM components' ranking. Regarding creativity, entrepreneurship as important and there is a high tendency for faculty members to share knowledge in some cases make it totally clear that the Isfahan University of Medical Sciences is similar to Kerman. On the other hand, inappropriate organization of official meetings for knowledge sharing, weak performance of independent research teams, and interorganizational networks are some of the structural weaknesses of both Universities. Results of the study conducted at Ferdowsi University of Mashhad showed that KM internalization scored the highest for this University and socialization, externalization, and combination scored lower. Individualism and a higher tendency of the faculty members of this University to internalize knowledge and compete with others has resulted in higher scores for internalization and socialization (27). The results of this study are contrary to the results of our study in terms of the ranking for KM component and the main reason for that is the different attitudes of faculty members in two Universities, which is affected by the cultural and organizational environment in the Ferdowsi University of Mashhad. Faculty members exhibit good relations with their colleagues and are show high levels of cooperation and participation spirit. In addition, independent research teams and inter-organization networks are used to optimally exchange knowledge. Meanwhile, in the Kerman University of Medical Sciences, the relationship of faculty members is not optimal for the exchange of knowledge and inter-organizational networks and independent research teams are not used appropriately. In a study conducted in organization X (the name of which is not mentioned due to security concerns) to determine KM status, the Nonaka and Takeuchi questionnaire was used. Based on data analysis, KM externalization is at the highest level in this organization. Then, combination, internalization, and socialization score closely behind externalization (22). According to the analysis conducted, it can be said that managers of this organization are more willing to share and exchange their knowledge and experiences, compared to internalizing it and competing with each other. This result correlates with the results of our study. Similar organizational cultures and structures are the main reason for the observed similar results. A high tendency for the staff to mention organization, regarding creativity and entrepreneurship is important. Cooperation of employees with organizations similar to their own organization and encouraging staff to exchange and share knowledge are some similarities between organization X and the Kerman University of Medical Sciences that led to similar results. Based on the results of the study conducted at the Isfahan University of Medical Sciences, KM internalization among faculty members occurs at the highest level and socialization, externalization and combination score lower (32), while the results of the present study are relatively contrary to the results of the Isfahan study. The reason for this difference is different organizational cultures and structures in study area. Faculty members of the Isfahan University of Medical Sciences have performed well in relationship with their colleagues, they organized official meetings to exchange knowledge and access proper information. In addition, they use independent research teams and inter-organizational networks to optimally exchange knowledge. Although faculty members at the Kerman University of Medical Sciences are willing to exchange knowledge and policy of university is in such a way that it emphasizes participation and entrepreneurship. They exhibited a weak performance in terms of establishing independent research teams and inter-organizational networks. The findings of the study conducted in Japan showed that, in a state educational institute, the average $\mathrm{KM}$ is 3.3 and in a private educational institute that was studied, it scored high (33). The results obtained for the state educational institutes correlate with the results of our study. In the present study, the relationship between the demographic variables, including gender, age, academic rank, total employment history, and employment history as a faculty member, with KM dimensions was investigated and according to the obtained results, no significant relation was observed between the studied demographic variables and the four KM dimensions. In other words, it can be stated that the demographic variables of faculty members should not be not regarded as important factors in performance. In this regard, the results of the study conducted at the Isfahan University of Medical Sciences showed that there was no significant relation between the demographic variables of age, gender, and major with KM; however, a significant relation exists between scientific rank and 
employment status with KM (31). In addition, in another study conducted in Bojnord investigating the relation between demographic variables and KM, it can be concluded that there was no significant relationship between degrees, major, or management level with KM (32). In another study conducted at the Isfahan University of Medical Sciences, the relation between demographic variables (age, gender, major, degree, academic rank and employment history) and KM is not shown to be significantly similar to the present study (22).

\section{Conclusions}

In summary, the findings of this study showed that knowledge exchange processes at the Kerman University of Medical Sciences are performed relatively successful in terms of combination (converting explicit knowledge to explicit) and externalization (converting implicit knowledge to explicit), as well as holding meetings and group meetings and converting ideas into reality. However, internalization (converting explicit knowledge to implicit) and socialization (converting implicit knowledge to implicit) rank low, which is the result of faculty members' weakness in expressing individual thoughts and imagination, and then talking about them. The implied importance of these findings is that, considering the status of KM dimensions, the strategy of Universities to KM can be determined. Therefore, these results suggested to the managers and deans of various faculties at the Kerman University of Medical Science to provide the required background for development of the University towards knowledge excellence by selecting knowledge-oriented strategy and implementing KM project regularly and systematically. Conducting a complementary study to determine KM status using the Nonaka and Takeuchi model in other Universities of Kerman, as well as Universities of medical sciences all across the country, can provide an appropriate course for later research in this area.

\section{Acknowledgments:}

The authors of this paper appreciate the cooperation of the research deputy of the Kerman University of Medical Sciences for providing required background for implementing the project and collecting necessary data for this research. In addition, the all the faculty members participated this study are appreciated. This paper was the result of research project number 94.10.06.22653 and its budget was provided by the research center of the health school at the Kerman University of Medical Sciences.

\section{Conflict of Interest:}

There is no conflict of interest to be declared.

\section{Authors' contributions:}

All authors contributed to this project and article equally. All authors read and approved the final manuscript.

\section{References:}

1) Musapoor H. review and identify problems and barriers to sharing knowledge, case study Bahonar University of Kerman. Institute of Islamic and Iranian culture. 2010.

2) Wang SH, Noe RA. Knowledge sharing; a review and direction for future research. Human Resource Management Review (HRMR). 2010; 20(2): 115-31. doi: 10.1016/j.hrmr.2009.10.001.

3) Hasan zadeh M. Infrastructural barriers to knowledge management in Iran. Iranian on Knowledge Management Conference, Tehran. 2007.

4) Bhatt G. Knowledge management in organizations: Study the interaction of technology, skills and human. Journal of Information Science (JIS). 2008; 18(1,2): 76-83.

5) Parsa A, MehrAlizadeh Y, Zamani E. The Status of knowledge management based on (SECI) In Ahvaz Chamran University and its relationship with organizational culture. Journal of Iranian Higher Education. 2010; 3(3): 87-113.

6) Aref nezhad M, Amirkhani T, Sobhani M. Explain success factors of information systems with an emphasis on the role of institutional and organizational learning. Journal of information technology management (JITM). 2012; 4(12): 89-114.

7) Jaberi A, Salimi M, Khazaee J. An investigation the $\mathrm{f}$ effects of intrinsic and extrinsic motivation on knowledge sharing employee of Sport organizations. Journal of Sport Management (JSM). 2013; 5(16): 5575 .

8) Gold AH, Malhotra A, Segars AH. Knowledge management: an organizational capabilities perspective. Journal Management Information System (JMIS). 2001; 18(1): 185-214.

9) Gupta B, Iyer LS, Aronson JE. Knowledge management: practices and challenges. Industrial Management \& Data Systems. 2003; 100(1): 17-2. doi: 10.1108/0263557001273018. 
10) Keshavarzi A, Yektaee M. Removing barriers of knowledge sharing in the organization based on the Islamic teachings. Iranian Journal of Management in the Islamic University. 2012; 1(2): 123-42.

11) Lajvardi J, Khanbabaee A. survey facilitation factors of knowledge management in work teams. Journal of management knowledge. 2007; (76): 97-116.

12) Rafatee H, Hasanavi R, Beh Azin F, Bani Taba A. Evaluation the pattern of knowledge management in a Military research center. J Mil Med. 2008; 10(3): 237-52.

13) Sufi Jahanyar B. Management the organizational Knowledge: Strategies, Processes and organizational structures in knowledge oriented organization. 2011. Tehran.

14) Hoq KMG, Akter R. Knowledge Management in Universities: Role of Knowledge Workers. Bangladesh Journal of Library \& Information Science. 2012; 2(1): 92-102. doi: 10.3329/bjlis.v2i1.12925.

15) Rahman Seresht H, Simar Asl N. study the knowledge gaps: research in Iran's Petrochemical Research \& Technology center of Tehran. International Journal of Management Sciences. 2008; 3(10): 37-61.

16) Shami M. Identify the factors affecting on sharing of knowledge in projects management. Ph.D. Thesis. School of Management in Tehran University. 2008

17) Wang CL, Ahmed PK. Structural dimension for knowledge based organization. Measuring Business Excellence. 2003; 7(1): 51-62. doi: 10.1108/13683040310466726.

18) Rahnavard F, Sadr F. The relation between perception of employee's Knowledge sharing culture and organizational factors in governmental agencies. Journal of Productivity Management. 2009; 2(8): 51 -74.

19) Mir Ghafuri H, Sadeghi Z, Saberi H. Analysing the barriers of knowledge sharing in government organizations. International Conference on Knowledge Management. 2008.

20) Choy CS. Critical success factors to knowledge management implementation: A holistic approach. In: Knowledge Management International Conference and Exhibition 2006, The Legend Hotel Kuala Lumpur. 2006.

21) Minouee M, Pourzarandi ME, Naderi N. Assessment the knowledge management by NonakaTakuchi model. Management Accounting Quarterly. 2010; 3(4): 49-58.

22) Zare F. Survey of knowledge management based on Nonaka theory and its relationship with organizational culture. Journal of Educational Research. 2007; (11): 59-74. doi: 10.1080/00220671.2014.909767.

23) Karamitri L, Talias MA, Bellali T. Knowledge management practices in healthcare

24) Alavi M, Leidner DE. Review: Knowledge management and knowledge management systems: Conceptual foundations and research issues. Management Information System quarterly. 2001; 25(1): 107-36. doi: $10.2307 / 3250961$.

25) Rabiee A, Houshyan Sabet Lahijani M. Knowledge Management in Payam Noor University Analyzing the Status of Items Affecting Key Indicators of Knowledge Management. Higher Education Letter. 2014; 7(26): 109-30.

26) Amiresmaili MR, Nekooi Moghadam M, Khosravi S, Mirzaei S, Oroomiei N. The Relationship between Organizational Culture Components and Knowledge Management. Health Information Management. 2015; 11(6(40)): 770-8.

27) Hosein Gholizadeh R, Shabani Varaki B, Mortazavi S. Relation between organizational culture and knowledge management in higher education. Journal of studies in education and psychology. 2005; 6(1): 527.

28) Shirvani A, Safdarian A, Alavi A. Scale Survey of Knowledge Management's Process Mastery (Isfahan University of Medical Sciences' Reading Scale). Health Information Management. 2009; 6(1): 75-82.

29) Sepid Medical Newspaper. 2015; (738).

30) Hosein Gholizadeh R. The Status of knowledge management based on Nonaka model in Ferdowsi University of Mashhad and its relationship with organizational culture. Master's thesis. Faculty of Educational Sciences Mashhad Ferdowsi University. 2007.

31) Rajaeepour S, Rahimi H. Study the relationship between the conversion of knowledge management and performance of faculty members of Esfahan university. International Journal of Humanities and Social Sciences Management. 2008; 8(4): 59-75.

32) Nadi MA, Bakhtiar Nasrabadi HA, Farahmandpour M. The analysis of the relationship between knowledge management dimensions and organizational learning levels between faculty members of Esfahan university educational year of 2009-2010. Journal of Educational Sciences. 2010; 3(11): 107-30.

33) Songsangyos P. The knowledge management in higher education in Chiang Mai: A comparative review. Procedia-Social and behavioral sciences. International Conference on Education \& Educational Psychology. 2012; 69(24): 399-403. doi: 10.1016/j.sbspro.2012.11.426. 